\title{
O PENSAR E O AGIR EM JOSUÉ de CASTRO: DILEMAS E ESTRATÉGIAS PARA O DESENVOLVIMENTO DO NORDESTE AÇUCAREIRO
}

\author{
THINKING AND ACTING IN JOSUÉ DE CASTRO: DILEMMAS AND STRATEGIES \\ FOR THE DEVELOPMENT OF NORTHEAST SUGAR BOWL
}

\author{
Inã Cândido de Medeiro \\ 1 Universidade Federal de Pernambuco \\ Doutorando no Programa de Pós-Graduação Sociologia, Brasil, e-mail: inamedeiro@gmail.com
}

\author{
ARTICLE INFO \\ Article history: \\ Received 2019-06-22 \\ Accepted 2019-09-06 \\ Available online 2019-09-06
}

Palavras-chave: Alimentação. Desenvolvimento. Fome. Josué de Castro. Nordeste Açucareiro

Keywords: Food. Development. Hunger. Josué de Castro. Northeast. Sugar Bowl

RESUMO. Este trabalho versa sobre o pensar e o agir de Josué de Castro como forma de auxiliar na compreensão sobre os dilemas nacionais para lidar com o fenômeno da fome, sobretudo no Nordeste brasileiro. Ao lado do tema relativo às questões alimentares e à fome, Castro procurava destacar os aspectos fundamentais das possíveis estratégias de desenvolvimento. Seu pensamento ganhou relevância com a disseminação do debate sobre o desenvolvimento no âmbito nacional iniciado no final da década de 1940. O fio condutor do argumento do intelectual pernambucano passava pela defesa de um desenvolvimentismo social e humanista, antes que apenas focado no crescimento econômico. A partir da análise do pensamento político e social de Josué de Castro, busca-se identificar quais seus principais pressupostos analíticos, diagnósticos e estratégias desenvolvimentistas apresentadas com vistas à solução para o flagelo da fome, particularmente do Nordeste açucareiro, da Zona da Mata. Para o autor, essa região sofria os efeitos negativos de séculos de colonização ibérica pautada na exploração agrícola, no latifúndio e na monocultura. A pretensão é reconhecer através da obra Geografia da fome e do diálogo com outros intelectuais, o conteúdo da formulação de Castro, além de suas continuidades e inflexões referentes aos seus escritos ao longo de sua trajetória. Assim, a retomada do pensamento de Josué de Castro se mostra relevante não somente devido a sua importância socio-histórica, mas pelo motivo da persistência dos problemas e desafios para o desenvolvimento do Nordeste e do Brasil, os quais tornam atuais suas ideias e seus projetos.

ABSTRACT. This work deals with the thinking and acting of Josue de Castro as a way to help in
understanding the national dilemmas to deal with the phenomenon of hunger, especially in the Brazilian
Northeast. Alongside the issue of food issues and hunger, Castro sought to highlight the fundamental
aspects of possible development strategies. His thinking gained relevance with the dissemination of the
debate on development at the national level beginning in the late 1940s. The guiding thread of the
Pernambuco intellectual's argument was to defend a social and humanistic developmental rather than
just focused on economic growth. Based on the analysis of Josué de Castro's political and social
thought, it is sought to identify the main analytical assumptions, diagnoses and developmental strategies
presented with a view to solving the hunger scourge, particularly in the Sugar Northeast, Zona da Mata.
For the author, this region suffered the negative effects of centuries of Iberian colonization based on the
farm, the latifundio and the monoculture. The pretension is to recognize through the work Geography of
the hunger and the dialogue with other intellectuals, the content of the formulation of Castro, besides its
continuities and inflections referring to its writings throughout its trajectory. Thus, the resumption of
Josué de Castro's thinking is relevant not only because of its socio-historical importance, but also 
because of the persistence of the problems and challenges for the development of the Northeast and Brazil, which make current their ideas and projects.

\section{Introdução}

A partir da análise do pensamento político e social do médico, geógrafo e sociólogo Josué de Castro, pretende-se identificar quais são os seus principais diagnósticos e estratégias desenvolvimentistas apresentadas na obra Geografia da Fome com vistas à solução do dilema da fome e dos impasses da pobreza e da desigualdade, sobretudo no Nordeste açucareiro, da Zona da Mata. A justificativa para a definição dessa abordagem se deu por tratar-se, segundo o autor, da região onde se verificavam os maiores índices de subnutrição e pobreza do país.

É importante destacar que o campo do pensamento político e social brasileiro assumiu para si essa tarefa de "pensar o pensamento" dos intérpretes célebres do Brasil. Para tanto, empreende-se um esforço de análise de textos, contextos, trajetórias, ações, ideias e as formas de recepção de pensamentos em outros momentos históricos. "Entendemos que essas são condições para aprofundar e aperfeiçoar o conhecimento sobre a sociedade brasileira nas várias dimensões desse processo, bem como dos próprios instrumentos de análise da área de pesquisa" (SCHWARCZ; BOTELHO, 2011, p. 14).

Desse modo, busca-se investigar o pensamento e a ação de personalidades públicas, de cientistas e de políticos que dedicaram a vida enfrentando os dilemas que assolam nossa nação. Cada intérprete do Brasil privilegia temas, indagações e produz seu pensamento em um determinado contexto (BRANDÃO, 2007).

No caso de Josué de Castro, ele se inscreveu entre os intelectuais e cientistas que apresentam formas inovadoras de explicar a realidade brasileira. Investigar o pensamento do autor ganha importância devido aos seus mais de quarenta anos de intenso debate e ação no combate à fome. Para isso, ele mobilizava diversas áreas do saber como a biologia, a fisiologia, a nutrição, a geografia, a história, a sociologia, as relações internacionais, a economia, além da literatura ${ }^{1}$.

Em 1951, Josué de Castro publicou a primeira edição de Geopolítica da fome. Contudo, em 1946 o autor já havia publicado Geografia da Fome, livro que marcou o debate na vida acadêmica e política ao abordar o projeto de desenvolvimento forjado por diversos matizes intelectuais desde a década de 1940.

Apesar da grande notoriedade nacional e internacional, há poucos estudos sistemáticos publicados sobre o pensamento político e social de Josué de Castro. Para Nascimento (2012),

\footnotetext{
${ }^{1}$ No primeiro ano de exílio, Castro rememorou os momentos de sua infância no Recife e escreveu seu único romance: Homens e Caranguejos. Traduzido em várias línguas, foi adaptado para o teatro por Gabriele Cousin com o título: Le Cycle du Crabe ou Les Aventures de Zé Luis, Maria et Leurs fils João (RONDINI, 2012).
} 
dentre os diversos autores que pesquisaram sobre a trajetória intelectual e política de Josué de Castro, a maioria afirma que suas obras precisam ser mais conhecidas e estudadas ${ }^{2}$, pois seu trabalho continua sendo uma fonte rica de entendimento para um fenômeno ainda tão atual e complexo como a fome ${ }^{3}$.

Segundo Nascimento (2010), ao lado do tema relativo às questões alimentares e à fome, Castro procurava destacar os aspectos fundamentais das possíveis estratégias desenvolvimentistas. Lima (2012), por sua vez, apontava que a obra de Josué de Castro, ao destacar a ocorrência da fome no Brasil e no mundo, buscava demonstrar a conexão entre as carências nutricionais e alimentares e as dificuldades de construção de estratégias de desenvolvimento. Partindo desses pressupostos, evidencia-se que o fio condutor do argumento do autor passava pela defesa de um desenvolvimentismo social, antes que apenas focado no crescimento econômico.

\section{O Nordeste açucareiro em Geografia da fome}

A obra Geografia da fome se tornou referência fundamental para compreender a questão alimentar no Brasil, além de incluir esse tema no centro da agenda de debates sobre a questão do desenvolvimento e do humanismo. A partir dessa obra, Josué de Castro evidenciou que o fenômeno da fome em todo mundo, não era exclusivamente biológico, mas possuía um caráter multidimensional: cultural, social, político e econômico.

O sociólogo Alberto Guerreiros Ramos (1995), ressaltava no texto Introdução crítica à sociologia brasileira que a obra Geografia da fome deveria ser colocada entre os livros prioritários para o conhecimento dos problemas do país. A importância do escrito residiria principalmente na forma pela qual Castro retratava o fenômeno da fome coletiva no Brasil, analisando cinco regiões classificadas pelo autor: Amazônica, Nordeste açucareiro, Sertão do Nordeste, Centro e Sul.

Castro (1980) destacava os problemas alimentares em cada região e demostrava que a fome não era apenas um fenômeno individual, mas também coletivo e universal. Para ele, esse fato dificilmente pode ser compreendido isoladamente, pois é parte de um conjunto de desigualdades que se combinam e se somam nos diferentes lugares e nas diferentes épocas (CARNEIRO, 2003).

\footnotetext{
${ }^{2}$ A escassez de estudos sistematizados sobre o autor se deve, entre outros motivos por seu exílio em Paris após sua expulsão do Brasil em seguida ao golpe civil-militar de 1964. Este fato tornou Castro um "ilustre desconhecido" em seu próprio país, "mesmo depois do regime militar em que os livros de Castro foram considerados subversivos, predominou o silêncio sobre suas obras, sobretudo nos cursos de Ciências Sociais do Nordeste" (NOGUEIRA; SANTOS, 2008, p. 96).

3 O relatório Luz da Agenda 2030, elaborado por vinte entidades, da sociedade civil apresentado no ano de 2017 sobre o desempenho do Brasil nos cumprimentos dos objetivos para o desenvolvimento sustentável, alertou que há um risco enorme do país voltar para o mapa da fome. Entre os principais motivos destacados no documento: o crescimento do desemprego, os cortes de benefícios do Bolsa Família, o aumento do custo de vida e o congelamento dos gastos públicos nos próximos vinte anos.
} 
Segundo o autor (1980), a explicação da fome no Brasil deveria ser buscada a partir do processo histórico do colonialismo. Segundo Castro, a subordinação à metrópole, na relação global de poder dos países ricos sobre os pobres, no sistema socioeconômico escravocrata, no cercamento da terra e desapropriação dos povos nativos de seus territórios e de um mercado voltado predominantemente para o exterior, baseado no modelo latifundiário monocultor, aprofundou o cenário de desigualdade social do país.

Referente à área da Zona da Mata, Castro defendia que o flagelo da fome não possuía causas naturais, como sugeriam diversos autores ao relacionavam as carências regionais ao fenômeno das secas. O autor denunciava que essa era uma das regiões que sofria as mais terríveis consequências da ausência de desenvolvimento, resultantes de séculos de colonização ibérica pautada na exploração agrícola, no latifúndio e na monocultura canavieira, que geraram de forma permanente a fome endêmica e crônica.

É importante destacar que a cana-de-açúcar chegou ao Brasil, pelos colonizadores portugueses no início de século XVI. Sua cultura foi iniciada através da feitoria situada na costa do Itamaracá. Para Andrade (2007), a civilização do açúcar propiciou a formação de uma sociedade dominada por grandes e médios proprietários de terra que viviam em propriedades luxuosas, dispondo de inúmeros serviçais, além de artífices especializados na produção do açúcar e aguardente. Os serviçais, que eram os índios nativos da América, foram em seguida substituídos pelos escravos negros da África. Os escravos eram divididos predominantemente em dois grupos: os dos eitos, que trabalhavam na agricultura, e os domésticos, que eram destinados aos serviços na Casa Grande, gozando de favores e regalias.

A partir do século XVI, o açúcar da cana, utilizado como alimento e estimulante, expandiu-se por toda Europa. O mesmo aconteceu com o Brasil, chegando primeiro a áreas menos povoadas, sobretudo o sertão. A cultura da cana foi cultivada em pequenas parcelas ou pelos agricultores livres, tendo como finalidade de produzir a cachaça e tabletes de açúcar, chamados de "rapadura". Essas unidades de produção eram conhecidas como engenhos rapadureiros, que permaneciam "primitivos" até o século XX, movidos pela tração animal, em geral bovina. Por outro lado, os engenhos no litoral "evoluíram" do engenho movido a tração animal, os chamados engenhos das bestas, para os engenhos reais movidos a água, para os engenhos a vapor, já no século XIX e, finalmente, para usinas de açúcar de pequeno, médio e grande porte" (ANDRADE, 2007, p. 32).

A civilização açucareira passou a ter importância tanto social como econômica na vida e culturas brasileiras, principalmente na região da Zona da Mata no Nordeste, como teve o café e o ouro no Sudeste brasileiro. Em sua obra Nordeste: Aspectos da Influência da Cana sobre a Vida e A Paisagem do Nordeste do Brasil (2004), o sociólogo pernambucano Gilberto Freyre descrevia de forma nostálgica o "seu Nordeste açucareiro" como: 
O Nordeste das árvores gordas, das sombras profundas, de bois pachorrentos, de gente vagarosa e às vezes arredondados quase em Sancho panças pelo mel do engenho, pelo peixe cozido com pirão, pelo trabalho parado e sempre mesmo, pela opilação, pela aguardente, pela garapa da cana, pelo feijão de coco-(FREYRE, 2004, p. 45).

Já Josué de Castro (1980), enfatizava outro tipo de Nordeste açucareiro: do extrativismo das florestas tropicais, das vacas magras, o da exploração colonizadora através da mão de obra escrava, vinculada à monocultura açucareira, das pequenas propriedades agrícolas engolidas pelos latifúndios, dos tabus e doenças alimentares; de uma população assolada não só por uma monotonia alimentar, tal como pelos efeitos nefastos da fome. Assim, Castro relatou que quando se pesquisa sobre as condições de alimentação do Nordeste açucareiro, percebe-se o contraste entre as oportunidades naturais e a extrema escassez dos recursos alimentares da região.

O autor (1980) afirmava que o fenômeno da fome na Zona da Mata passava a exercer efeito despótico sobre os grupos humanos que lá viviam. A princípio, os primeiros colonos portugueses promoveram uma tradição alimentar caracterizada pela riqueza e variedade do cultivo de verduras e frutas. Contudo, desde cedo, perceberam nesse local um potencial imenso para o cultivo da cana-de-açúcar, concentrando os trabalhadores nessa atividade.

Para Castro (1980), o colonizador ibérico, ao buscar apenas a prosperidade econômica dos latifúndios da colônia através da implementação da monocultura canavieira, não aproveitou os recursos naturais para adquirir uma base alimentar diversificada. Com o tempo e a influência de séculos de ação ambientalmente degradante do colonizador europeu, essa região de florestas tropicais foi profundamente modificada, predominando os campos abertos e desmatados, onde se disseminaria a monocultura da cana.

Em contraposição à ação dos colonizadores, Castro (1980) afirmava que os índios haviam contribuído para os preparos de refeições variadas, embora não tivessem conseguido impor os seus hábitos e processos alimentares rudimentares, muito diversos dos regimes alimentares dos europeus. Mesmo assim, eles procuravam defender as florestas contra a destruição das matas, mantendo em alguns momentos o equilíbrio em algumas áreas contra a ação predatória do colonizador europeu.

Para Castro (1980), ainda mais favorável à nutrição adequada teriam sido os hábitos alimentares dos escravos negros. Os povos africanos que vieram a constituir a escravaria brasileira cultivavam diversas plantas e mantinham uma alimentação variada, influenciando positivamente o regime alimentar no Nordeste, "desobedecendo às ordens do senhor e plantando às escondidas seu roçadinho de mandioca de batata, de feijão, de milho. Sujando aqui e acolá, o verde monótono dos canaviais com manchas diferentes de outras culturas" (CASTRO, 1980, p. 133). 
Não obstante, as tradições alimentares dos índios e negros tiveram amplitude limitada na garantia de uma alimentação adequada, não podendo fazer frente à monocultura latifundiária, promotora do empobrecimento e rápido esgotamento do solo. Para Castro, a própria desvalorização da cana teria ocorrido devido à destruição desmensurada das matas primitivas, que com o tempo teria resultado na perda de importância econômica das atividades açucareiras do Nordeste. Posteriormente, as usinas - através do uso de suas engrenagens, dejetos e caldas - teriam agravado ainda mais a situação alimentar das populações dessa região, devastando os rios e os recursos alimentares, causando a matança de diversas formas de vida aquática, como peixes e crustáceos.

Ainda em relação ao regime alimentar da região, Castro possuía profundas discordâncias com Gilberto Freyre. O autor de Casa Grande \& Senzala afirmava que, na região Nordeste, os mais bem alimentados estavam nos dois extremos da sociedade estamental: o senhor de engenho e o escravo. Contudo, Castro destacava que quase desde o início da colonização, a alimentação dos habitantes dessa região teria sido escassa e de má qualidade.

Com base nos inquéritos realizados por Josué de Castro na cidade do Recife, percebeuse uma monotonia alimentar e de quantidades calóricas insuficientes na dieta de seus habitantes, que se alimentavam quase exclusivamente de farinha, de feijão, charque, açúcar e café. $O$ inquérito também constatou que o Nordeste açucareiro era uma das zonas onde a subalimentação seria mais acentuada no país. Segundo Castro, "a monocultura da maneira que foi estruturada, embora gerasse riquezas para o colonizador, contribuiu de forma negativa para o desiquilíbrio não só alimentar como social do Nordeste açucareiro" (CASTRO: 1980, p. 169).

Segundo Castro (1980), muitos dos tabus alimentares da Zona da Mata surgiram devido às interdições dos senhores de engenho em relação aos padrões alimentares de seus escravos e trabalhadores. O fundamento econômico - como no caso do cultivo do açúcar no Nordeste - teria sido o principal responsável por esses tabus. "A verdade é que esses tabus se constituíram como uma espécie de policiamento moral que os proprietários mantinham para defesa dos seus bens" (CASTRO, 1980, p. 154).

Por meio de uma perspectiva sanitarista-desenvolvimentista, Castro buscava, através da sua obra Geografia da fome, construir uma ferramenta teórico-metodológica que integrasse as tendências científicas às políticas públicas vigentes, fomentando uma interlocução entre as questões nutricionais e as reformas de base, integrando o pensamento e a reflexão acadêmica à ação concreta com vistas à transformação da realidade social. Para Bizzo (2009), ao longo de sua trajetória Castro defendeu um projeto modernizador, propondo uma alimentação adequada, fundada em um padrão dietético racional, como pressuposto para o desenvolvimento humano e também material.

É possível perceber a agudez das observações empíricas de Castro na classificação das condições alimentares, e das carências do Nordeste açucareiro, marcado pela 
subalimentação. Para o autor, as proibições, superstições e restrições alimentares não possuíam qualquer embasamento biológico. Conforme apontava, muitas dessas restrições, como no caso das frutas, certos tipos de doces e verduras, ainda permanecem enraizadas nas tradições e costumes alimentares dos nordestinos das áreas onde vigorou a civilização da cana.

Josué de Castro afirmava que a maior parte das endemias no Nordeste, desde o início da colonização, teriam como principal responsável a fome, pois "as chamadas doenças de massa se enxertam sobre os quadros da fome como uma decorrência natural" (CASTRO, 1980, p. 168). Todo o povoamento inicial teria alcançado uma concentração favorável para o desenvolvimento nessa região, mas em seguida, com o avanço do latifúndio monocultor açucareiro, toda a população da Zona da Mata teria sido prejudicada, agravando o desequilíbrio social e econômico na região.

\section{O pensamento desenvolvimentista e a questão regional em Josué de Castro}

O tema do desenvolvimento percorre mais de quatro séculos no pensamento ocidental e está intimamente vinculado historicamente à noção de progresso, modernização e evolução social. Segundo Cepêda (2012), o termo desenvolvimento é um conceito polissêmico em constante disputa, com inúmeras controvérsias e significados que percorrem várias áreas, atravessando o debate intelectual e político ao longo da história.

Cepêda (2012) afirmou que Condorcet e Herder foram os primeiros a refletirem sobre as transformações das relações sociais em face de processos de mudança de partidos de uma dimensão evolutiva, que propicie o desenvolvimento dos humanos em uma determinada sociedade. Dentro de uma ampla diversidade teórica que percorre desde a metafísica ao materialismo, pensadores como Kant, Hegel, Augusto Comte, Adam Smith Karl Marx e Engels procuraram compreender e questionar a evolução e suas determinações, fortalecendo a perspectiva epistemológica da filosofia histórica e dos processos de mudanças. "Independentemente do estabelecimento do motor ou sujeito dessa mudança (razão, história, classe social ou indivíduo) ou do telos de sua realização, o cânone do desenvolvimento assentou bases sólidas no pensamento intelectual dos séculos XVIII em diante" (CEPÊDA, 2012, p. 77).

Separando a noção de desenvolvimento e desenvolvimentismo, Cepêda (2012) afirma que o desenvolvimentismo está relacionado ao avanço do modo de produção capitalista, a divisão social do trabalho e a noção de centro e periferia. "De maneira geral, pode-se definir desenvolvimentismo como um projeto de transformação social profunda, operada politicamente de maneira racional e orientada pelo Estado, vinculando economia e avanço social" (CEPÊDA, 2012, p. 79). 
Para Magalhães (1997), o conceito de desenvolvimento embora abrangente e utilizado por autores de inúmeras áreas do conhecimento e vertentes ideológicas, assumiu um papel central para a compreensão e sistematização do pensamento social e político de Josué de Castro, desde a publicação de Geografia da fome. Já o pensamento desenvolvimentista de Castro, ganhou relevância com a disseminação do debate sobre a questão do desenvolvimento no âmbito nacional iniciado no final da década de 1940. A identificação das ideias desenvolvimentistas ${ }^{4}$, encontravam-se presentes nessa obra e foram aprofundadas em seus trabalhos posteriores e nas reedições do livro de 1946.

No entanto, podemos afirmar que o debate sobre o desenvolvimentismo no Brasil ganhou maior atenção no auge do governo de Juscelino Kubistchek. Nos anos 1950, o tema do desenvolvimento tornou-se hegemônico no debate político e econômico nacional. Neste contexto, a região Nordeste voltou a ter maior destaque no cenário político, especialmente após a grande seca de 1958, que deu notoriedade ao flagelo regional da fome e às iniquidades sociais e econômicas condicionadas pelo latifúndio.

A miséria e as contradições estabelecidas pelo latifúndio nordestino ganharam ampla visibilidade especialmente com a organização das Ligas Camponesas, lideradas por Francisco Julião, que manteve grande proximidade com Castro e foi também eleito deputado pelo PTB pernambucano. Ambos tiveram uma participação ativa na defesa da reforma agrária no Congresso, destacando que o latifúndio seria um dos motores fundamentais da miséria e da fome no Nordeste.

A partir do final da década de 1950 a questão regional foi central na agenda política do país, destacando particularmente os desafios e dilemas a serem enfrentados no sentido do desenvolvimento regional, o que aproximou o pensamento e a ação de Josué de Castro e Celso Furtado (ANDRADE, 1997). Segundo Pereira (2011), as principais teses de Furtado foram expostas em vários artigos solicitados pelo Banco Mundial e que posteriormente foram reproduzidas em sua obra mais conhecida - Formação Econômica do Brasil (1958), no qual o autor buscava compreender o processo histórico da constituição da economia brasileira.

Assim como Celso Furtado e Caio Prado Júnior, Castro também se valia do estudo das questões relativas à formação histórica colonial do país para compreender os condicionantes do atraso e do "subdesenvolvimento" ${ }^{5}$ do país e, particularmente, do Nordeste. "Foram os

\footnotetext{
${ }^{4} \mathrm{O}$ projeto desenvolvimentista teve um papel crucial no processo de formação da modernidade brasileira. O movimento que buscava a construção da nação e a superação de suas deficiências e contradições iniciou-se a partir do século XIX, através dos interpretes do Brasil: Nabuco, Euclides da Cunha, Alberto Torres, Gilberto Amado, Oliveira Vianna, Sérgio Buarque de Holanda, Manoel Bonfim, Gilberto Freyre, entre outros. No entanto, ainda conforme destacou Cepêda (2012) e Magalhães (1997), os autores que lidaram com a questão econômica e que acentuaram o peso da colonização e a sua herança primária exportadora foram Roberto Simonsen, Caio Prado Junior e Celso Furtado.
}

5 "Vale observar que o conceito de subdesenvolvimento, que marcou a história das ideias no Brasil, é um conceito difuso e muito abrangente, usado por vários autores de diferentes matrizes ideológicas e de diferentes áreas do conhecimento: economistas, sociólogos, cientistas políticos, estudiosos das relações internacionais, historiadores e geógrafos. No entanto, a origem do termo subdesenvolvimento como categoria de análise dos países periféricos pode ser datada desde 1950. Antes disso, autores como Lênin, Rosa Luxemburgo e Leon Trotsky, Antoni Gramsci e mesmo Karl Marx denominaram diversas formas e vinculação entre 
interesses alienígenas que predominaram, orientando nossa economia para a exploração primária da terra e para a exploração das matérias primas assim obtidas "(CASTRO, 1980, p. 281).

Castro (1980) afirmava que a situação de desajuste havia se perpetuado devido à inaptidão do Estado brasileiro no sentido da promoção de um mínimo equilíbrio social, econômico e regional. O capital estrangeiro teria se expandido por meio de uma agricultura extensiva de produtos exportáveis, obstando o avanço de uma agricultura intensiva para a subsistência.

A metrópole e a Coroa haveriam privilegiado os interesses dos senhores de engenho, que amparados em um regime patriarcal, obstaram a ascensão social da maioria da população, propiciando a ampliação contínua da miséria e da fome, que se mostravam mais profundas no Nordeste. Para o autor, os governos demonstravam total incapacidade de impedir a interferência dos monopólios estrangeiros na economia, favorecendo a ampliação dos lucros de uma pequena parcela de proprietários agrícolas e do capital estrangeiro em detrimento do restante da população (CASTRO, 1980).

Para Castro (1980), o sistema econômico do Nordeste expressava uma forte subordinação em relação aos interesses mercantis das regiões mais desenvolvidas do país, mantendo inalteradas as condições sociais, a miséria e a fome no Nordeste. Reproduzindo o argumento hegemônico na época, o Nordeste manteria, segundo Josué de Castro, restos feudais ${ }^{6}$, os quais obstariam o desenvolvimento das forças produtivas de forma a impedirem o desenvolvimento da região.

Castro (1980) denunciava que a situação do Nordeste era ainda mais alarmante que a das outras regiões devido à concentração de um terço da população brasileira em seu território, contingente este submetido majoritariamente a uma situação econômica e alimentar precária. Essa assimetria se mantinha em função da ausência de políticas regionais que envolvessem opções diferenciadas na definição das taxas de câmbio, das tarifas e créditos, que beneficiavam as áreas mais industrializadas do país. O autor afirmava que grande parte dos recursos do Nordeste vinham sendo drenados para o Sul, ampliando o desnível econômico regional, que resultava na disparidade entre os índices de produção, de consumo e renda.

\footnotetext{
os países capitalistas avançados e as zonas subordinadas de múltiplas formas a eles. Mas só foi na década de 1950 que a palavra teve seu momento áureo, uma vez que foi sistematizada amplamente discutida e utilizada" (NASCIMENTO, 2012, p. 321)

${ }^{6}$ Em contraposição à tese feudal surge, a partir dos anos 1930, a abordagem que acentua a ligação do Brasil colônia com o mercado externo, inaugurada por Caio Prado Junior. "Castro não levava em consideração que o regime de propriedade colonial muito se difere do regime feudal europeu. No feudalismo não existia uma produção exclusivamente voltada para o mercado externo como o sistema colonialista, a que o Brasil é submetido desde os seus primórdios. No sistema feudal a terra servia praticamente para a própria subsistência dos seus arrendatários. O feudalismo é um fenômeno caracterizado pelo isolamento imposto ao seu feudo, em que não há trocas mercantis com outros feudos. Ora, ao contrário da unidade feudal, a unidade escravagista vive totalmente voltada para o mercado externo" (NASCIMENTO, 2012, p. 320).
} 
Para Castro, a situação política e econômica conspirava contra o desenvolvimento da região nordestina. Neste sentido, Castro apoiava as mobilizações sociais como forma de tomada de consciência da população sobre a situação de fome e destituição em que viviam os nordestinos (MAGALHÃES, 1997). Seriam necessárias ações do Estado e também da sociedade civil para que fossem possíveis transformações socioeconômicas que solucionassem os problemas seculares do Nordeste, promovendo uma maior distribuição das riquezas produzidas pelo país.

Assim como Celso Furtado, Josué de Castro também cerrou críticas ao modelo desenvolvimentista levado a cabo no país, que privilegiava os interesses dos estados e regiões mais industrializadas, amplificando as desigualdades regionais. Enquanto Furtado criticava a manutenção da "política hidráulica", produtora da "indústria da seca"7, focava nos aspectos econômicos relativos aos investimentos industriais e à ausência de políticas de caráter regional que atribuíssem atenção prioritária para as regiões subdesenvolvidas, particularmente para o Nordeste, Castro, por sua vez, direcionava sua atenção à questão nutricional. O desenvolvimentismo não vinha combatendo os flagelos alimentares no país, ao contrário. Castro afirmava que "o que o Nordeste necessita é de algo bem diferente. É um tratamento do governo federal que não seja da metrópole em face da colônia" (CASTRO, 1980, p. 285). 'Teria faltado 'coragem' ao governo para enfrentar as desigualdades regionais adequadamente, o que comprometeria todo o plano de desenvolvimento nacional" (CASTRO, 1980, p. 289).

Apesar de estabelecerem um processo de industrialização na Zona da Mata, em face especialmente do apoio à agroindústria da cana, as políticas federais voltadas para essa região não rompiam os ditames coloniais, preocupando-se em desenvolver apenas aquilo que já estava desenvolvido e de enriquecer aqueles poucos que já eram privilegiados pelo modo de produção vigente. O crescimento econômico não correspondia a um desenvolvimento social, que, para ele, representaria a consecução dos anseios da maior parte da população. "Para Josué de Castro a pouca importância dada pelo Estado à agricultura e ênfase na industrialização das regiões Sul e Sudeste do país ampliava o abismo social da fome" (MAGALHÃES, 2012, p. 582).

Castro defendia a integração plena da região Nordeste com o resto do Brasil. O país mantinha uma economia fragmentada, que beneficiava a parte do eixo Sul, considerada

\footnotetext{
${ }^{7}$ A expressão "indústria da seca" foi cunhada originalmente por Antônio Callado ao referir-se aos principais beneficiados com as políticas de construção de açudes, barragens e canais, e com as frentes de trabalho das obras contra as secas. Os latifundiários do Nordeste seriam estes beneficiários prioritários, reproduzindo e estimulando as desigualdades sociais no Nordeste e fomentando a perpetuação da miséria da maioria da população. Os recursos federais para as obras contra as secas antes que combater seus flagelos, mantinham os nordestinos à sombra do poder dos coronéis. $\mathrm{A}$ "indústria da seca" geraria a conservação das estruturas de poder e mantém a subordinação da região às economias do Centro-Sul do país, fortalecendo os latifúndios e a economia agrária arcaica. (GODOY, 2013).
} 
moderna e industrializada, em detrimento do eixo Norte, entendida como região arcaica e agrária.

Já em 1930, Castro passou a destacar que o desnível entre a produtividade agrícola e industrial do Nordeste seria uma das principais causas da ausência de desenvolvimento, tanto na Zona da Mata quanto no Sertão. O autor evidenciava que os índices de produtividade da agricultura nordestina tinham sido um dos mais baixos do mundo. $O$ atraso no setor agrícola era uma das principais causas da miséria e da fome na região. Como consequência do arcaísmo da agricultura teria havido um estrangulamento do setor industrial.

Segundo Castro (1980), o Nordeste teria a necessidade de se integrar na economia nacional, além de que precisaria de medidas, de âmbito privado e público, capazes de proporcionar melhorias não só na economia, como também na distribuição de renda. Não bastava o crescimento econômico, o desenvolvimento exigiria considerar principalmente os fatores humanos e sociais, estabelecendo a alimentação como prioridade. Um grau de desenvolvimento satisfatório para Castro e outros teóricos como Lebret ${ }^{8}$ e Furtado, consistiria em expandir as garantias mínimas de sobrevivência para todos, proporcionando uma alimentação adequada, saneamento básico, habitação, educação e saúde. Caberia ao Estado prover os meios para a garantia dessas condições sociais mínimas, sem as quais seria inócuo buscar o desenvolvimento, já que as garantias humanas fundamentais seriam pressupostos a qualquer estratégia desenvolvimentista.

A subcapitalização e o subemprego seriam obstáculos para a exploração racional das riquezas e potencialidades do Nordeste. "A concentração fundiária desestimulava o surgimento de uma economia regional dinâmica e desenvolvida" (CASTRO, 1980, p. 169).

Para o autor, nas áreas de latifúndio, com exceção das fazendas de cana-de-açúcar, se praticava uma agricultura primária sem assistência técnica, sem adubagem e seleção de sementes, resultando em uma produção e rendimento insatisfatório. Assim "o arcaísmo da estrutura agrária está intimamente ligado ao problema do desemprego, que é sem dúvida um dos fatores condicionantes da alta prevalência da fome no Nordeste". (CASTRO, 1980, p. 261). Castro apontava que além de se buscar aumentar o índice de produtividade da região, a indústria e a agricultura não podiam ser consideradas atividades antagônicas, ambas necessitavam de auxílio técnico e financeiro para diminuírem seus custos de produção, no

\footnotetext{
${ }^{8}$ Para Godoy (2014), percebem-se influências mútuas nas obras do padre dominicano Louis Joseph Lebret e Josué de Castro, que trabalharam juntos em diversas pesquisas sobre o Brasil, entre outros países e participaram do Conselho da FAO e da ONU. Os autores defendiam um desenvolvimento humano e integral, envolvendo não apenas os aspectos econômicos, mas também as dimensões: social, cultural, intelectual, científica e espiritual. Tanto para Lebret como para Castro, o desenvolvimento humano exigiria a garantia de condições mínimas de alimentação e nutrição. Para eles, a fome seria um obstáculo intransponível ao desenvolvimento social.
} 
sentido de propiciarem a ampliação do mercado e promoverem o aumento de oferta e demanda de empregos, permitindo a permanência da população nordestina em seu território.

O intelectual pernambucano também reservava especial atenção à situação da classe trabalhadora, estando sempre atento à desvalorização do salário e à exigência de poderem suprir suas necessidades básicas, como a alimentação, para se alcançarem maiores níveis de produtividade e desenvolvimento econômico e social. Conforme destacara Andrade (2005), o entrave ao desenvolvimento no Nordeste, para Castro, estava diretamente relacionado com as péssimas condições de vida dos trabalhadores rurais. Quando de sua formulação, ainda na Era Vargas, o salário mínimo e as demais leis trabalhistas voltaram-se exclusivamente para os trabalhadores urbanos, excluindo da plataforma de direitos sociais os trabalhadores rurais, que compunham a maior parte da população nordestina, privando de direitos e meios mínimos de subsistência a maioria desse contingente ${ }^{9}$.

A situação de penúria do trabalhador rural seria ainda mais grave, restringindo as oportunidades de consumo e geração de mercado interno, o que prejudicava as oportunidades de crescimento industrial. Longe de propor uma solução assistencialista para os trabalhadores, Castro defendia o salário mínimo e a reforma agrária, alinhando-se às reinvindicações do movimento sindical, umbilicalmente associado ao PTB.

Como destacado, era fundamental, para Josué de Castro (1980), a reforma agrária no Nordeste, não apenas na Zona da Mata, como sugeria Celso Furtado e os dirigentes da SUDENE. Sem reforma agrária o panorama de ampliação dos conflitos sociais se aprofundaria ainda mais.

Segundo o autor (1980), seria imprescindível a participação de toda sociedade no enfrentamento do tabu da reforma agrária com a mesma determinação com que deveria enfrentar o tabu da fome. Para ele, assim como a fome, a reforma agrária era um tema proibido, vergonhoso, escabroso e entendido como perigoso para a nação.

De acordo com Castro, "representa a política de desenvolvimento, o que se chama necessidade histórica, um imperativo ao qual não podemos fugir" (CASTRO, 1980, p. 294). Das diversas matizes do nacional-desenvolvimentismo, um dos temas divisores de águas foi exatamente a reforma agrária e os meios sugeridos de sua implementação. No campo do nacional-desenvolvimentismo, Castro divergia principalmente das vertentes que defendiam a

\footnotetext{
${ }^{9}$ Apenas em 1962, por meio do Acordo Campo, estipulado pelo governador de Pernambuco, Miguel Arraes, os cortadores de cana passaram a ter direitos trabalhistas, como jornada de trabalho de 8 horas e salário mínimo. Arraes promoveu negociações entre o governo, usineiros e trabalhadores para discutir o estabelecimento de deveres e direitos específicos voltados para os trabalhadores da Zona da Mata, garantindo, como resultado, um pagamento mais justo aos trabalhadores e a formalização. A partir de então, os trabalhadores da cana passaram a ser registrados em carteiras de trabalho, assim como incorporaram o direito de greve e de formação de sindicatos, assim como já era garantido aos trabalhadores urbanos (ANDRADE, 2005).
} 
prioridade à industrialização em detrimento do sacrifício dos investimentos destinados aos setores agrícolas.

O autor afirmava que a concentração das ações, estímulos fiscais e investimentos em um único setor estimularia um desequilíbrio que levaria regiões como o Nordeste açucareiro a sofrer os maiores impactos negativos, promovendo o estrangulamento da indústria nordestina e, consequentemente, da indústria própria brasileira. "Sendo imperioso o desenvolvimento econômico nacional deveria Governo e povo se unir através de um processo de mútua confiança e de mútuo interesse, a fim de que esse desenvolvimento não fosse sacrificado em sua execução por certas falhas inevitáveis, mas que deviam ser corrigidas a tempo para evitar um desastre econômico no país". (CASTRO, 1980, p. 297).

\section{Considerações finais}

O acompanhamento do pensamento de Josué de Castro identifica o autor no interior de uma longa linhagem intelectual. Assim, durante sua trajetória, Castro exerceu o papel de cientista, intelectual e membro da burocracia estatal. Seu modo de pensar e agir, o caracterizou como "homem da medicina e das ciências sociais, da tribuna parlamentar e das associações e dos centros de pesquisa que fundou e dirigiu, da literatura e do cinema" (MELO, 2012, p. 110). Portanto, Castro não foi apenas um intelectual acadêmico, seu engajamento contra a fome contribuiu para a formação do pensamento nacional desenvolvimentista do país e, particularmente, abriu caminho para os estudos futuros relacionados a (in) segurança alimentar e nutricional da população brasileira.

Perpassou nesse trabalho, a relação da dinâmica de interação do autor, da sua obra e o contexto social em que ela foi produzida. Embora pouco lembrado no campo das Ciências Sociais, o pensamento de Castro acerca do desenvolvimento iluminou o processo de interlocução sobre o tema, sempre em diálogo com outros intérpretes do seu tempo.

Ao analisar o pensar e o agir de Castro, deu-se ênfase aos diagnósticos acerca dos problemas relacionados a fome coletiva e das oportunidades de desenvolvimento, sobretudo do Nordeste açucareiro. "A partir do seu núcleo discursivo de politização da fome, defendeu sua posição social pragmática por parte da intelelligentsia, tendo em vista uma reconstrução nacional que tirasse o Brasil da condição de sub-nação" (BIZZO, 2009, p. 402).

Para compreendermos o lugar da questão do desenvolvimento do Nordeste açucareiro no pensamento de Josué de Castro através da obra Geografia da Fome, procurou-se contextualizar aspectos fundamentais da trajetória política e intelectual do autor. Portanto, observou-se aspectos da sua produção intelectual, de sua ação e constante diálogo com intelectuais, políticos e atores sociais de sua época, sobretudo da região nordestina. 
Segundo Castro (1980), a obra Geografia da Fome teve como propósito maior um instrumento de informação para a intervenção através de políticas públicas que pudessem de fato proporcionar algum tipo de melhoria e desenvolvimento social e econômico - tanto contra o quadro da fome como da miséria - para as regiões retratadas. No caso do Nordeste açucareiro, ele denunciava a necessidade de se compreender melhor o processo econômico, histórico e social que aprofundou a miséria e a fome advindas do latifúndio e da monocultura açucareira. Com isso, buscava, por meio de suas estratégias desenvolvimentistas, solucionar os dilemas que assolavam a região abordada.

Apesar de destacar os enormes desafios a serem solucionados pelo Nordeste e pelo Brasil para galgar avanços sociais e erradicar a fome, Castro assumiu uma postura otimista quanto ao futuro. Superados os gargalos econômicos e alimentares, acreditava que não só o Nordeste açucareiro, como todo o país poderia alcançar não apenas um crescimento efetivo, mas um desenvolvimento pleno.

\section{REFERÊNCIAS}

ANDRADE, Manuel Correia de. A Civilização Açucareira. In.: QUINTAS, Fátima (org.). A civilização do açúcar. Recife: SEBRAE / Fundação Gilberto Freyre, 2007.

ANDRADE, Manuel Correia de. Josué de Castro: O homem e cientista e seu tempo. Estudos Avançados, São Paulo, v.11, n.29, p.169-194, 1997.

ANDRADE, Manuel Correia de. A terra e o homem no Nordeste: contribuição ao estudo da questão agrária no Nordeste. São Paulo: Cortez, 2005.

BIZZO, Maria Letícia Galluzzi. Ação política e pensamento social em Josué de Castro. Boletim do Museu, Belém, v. 4, n. 3, p.401-420 Dez. 2009.

BRANDÃO, GILDO. Linhagens do pensamento político brasileiro. São Paulo: Aderaldo \& Rothschild, 2007.

CARNEIRO, Henrique. Comida e sociedade: uma história da alimentação. Rio de Janeiro: Ed. Campus, 2003.

CASTRO, Josué de. Geografia da Fome: o dilema brasileiro do pão e aço. Rio de Janeiro: Antares /Achiamé, 1980.

CASTRO, Josué de. Homens e Caranguejos. São Paulo: Ed. Brasiliense, 1967.

CEPÊDA, Vera Alves. Inclusão, democracia e novo-desenvolvimento: um balanço histórico. Estudos avançados, São Paulo, v.6, n.75, p. 77-90, maio de 2012.

FREYRE, Gilberto. Nordeste: aspectos da influência da cana sobre a vida e a paisagem do Nordeste do Brasil. São Paulo: Global, 2004.

FURTADO, Celso. Formação econômica do Brasil, 14ª ed. São Paulo, Nacional, 1976.

GODOY, José Henrique Artigas de. A práxis de Lebret: Economia Humana, desenvolvimentismo católico e o problema regional do Nordeste. Brasília: in: ENCONTRO DA ASSOCIAÇÃO BRASILEIRA DE CIENCIA POLÍTICA, 9., Brasília, Anais eletrônicos... Brasília, 
$<$ http://www.encontroabcp2014.cienciapolitica.org.br/resources/anais/14/1403729726 ARQU IVO Paper.ABCP.2014.pdf>. Acesso em: 31 jan. 2019.

GODOY, José Henrique Artigas de. Os Nordestes de Freyre e Furtado. Política \& Sociedade, [s.I.], v. 12, n. 24, p.61-88, 16 out. 2013. Universidade Federal de Santa Catarina (UFSC). http://dx.doi.org/10.5007/2175-7984.2013v12n24p61_Acesso em: 31 jan. 2019.

LIMA, Marcos Costa. A compreensão holística de Josué de Castro nas Ciências Sociais. In: MAGNO, Tânia Elias (org.) Josué de Castro. Rio de Janeiro: Fundação Miguel de Cervantes, 2012 (memória do saber).

MAGALHÃES, Rosana. Fome: uma (re)leitura de Josué de Castro. Rio de Janeiro: Editora FIOCRUZ, 1997.

MAGNO, Tânia Elias (org.) Josué de Castro. Rio de Janeiro: Fundação Miguel de Cervantes, 2012. (memória do saber).

MELO, Normando Jorge de Alburquerque. Josué de Castro: Um compromisso, ético, estético e pedagógico. In: SILVA, Tânia Elias Magno da (Org.). Josué de Castro: Memória do Saber. Rio de Janeiro: Fundação Miguel de Cervantes, 2012. p. 108-149.

NASCIMENTO, Renato Carvalheira, do. Três Combatentes da fome no Brasil: Josué de Castro, Betinho e Dom Hélder Câmara. In: CONGRESSO LATINO AMERICANO DE SOCIOLOGIA RURAL, 8., Porto de Galinhas - PE, 2010. p. 1-23.

NASCIMENTO, Renato Carvalheira, do. A contribuição de Josué de Castro para o sistema e a política nacional de Segurança Alimentar e Nutricional. In: MAGNO, Tânia Elias (org.) Josué de Castro. Rio de Janeiro: Fundação Miguel de Cervantes, 2012. (memória do saber) NOGUEIRA, Maria Aparecida Lopes; SANTOS, Mercês. Sociedade dos Mangues: Josué de Castro sempre in: MAGNO, Tânia Elias (org.) Josué de Castro. Rio de Janeiro: Fundação Miguel de Cervantes, 2012, (memória do saber).

PEREIRA, José Maria dias. Uma Breve história do desenvolvimentismo no Brasil. Cadernos do desenvolvimento, Rio de Janeiro, v. 6, n. 9, p.121-141, jul.-dez. 2011.

RAMOS, Alberto Guerreiro. Introdução crítica à sociologia brasileira. Rio de Janeiro. Editora UFRJ, 1995.

Relatório Luz da Agenda 2030 de Desenvolvimento Sustentável. Síntese: Disponível em: <htpp://actionaide.org.br/wpcontent/files_mf/1499785232Relatorio_sintese_v2_23jun.pdf> Acesso em: 05 jan. 2019.

RONDINI, Luiz Carlos. Homens e caranguejos: o diálogo entre arte, vida e ciência. In: SILVA, Tânia Elias Magno da (Org.). Memória do Saber: Josué de Castro. Rio de Janeiro: Fundação Miguel de Cervantes, 2012. Cap. 1. p. 163-181.

SCHWARCZ Lilia Moritz; BOTELHO André. Pensamento Social brasileiro: um campo vasto ganhando forma. Revista Lua Nova, São Paulo, no82, p. 11-16, 2011. 